\title{
Modeling of Double Source DC-DC Converter
}

\author{
Aashi Rathore ${ }^{\# 1}$, Vijay Kumar Tewari ${ }^{{ }^{2}}$ \\ \# Madhav Institute of Technology and Science, Gwalior, India \\ * Madhav Institute of Technology and Science Gwalior, India \\ \#aashirathore9315@gmail.com \\ *tewarivijay2012@gmail.com
}

\begin{abstract}
Abstract- This paper presents a new two-switch dc-dc converter belonging to higher order family and it performs boosting operation with respect to both the sources A multiple source DC-DC converter suitable to draw power from two different dc sources and feeding a common dc load is presented. The objective of this paper is to develop state-space and discrete-time model of the two-input converter, apply the interaction analysis to ensure power management and finding correct pairing of the controlled variables for developing controller.
\end{abstract}

\section{INTRODUCTION}

Reliability, accuracy and better load regulation are main issues of modern power supply. Demand of dc-dc power converter is increasing day by day in various applications such as hybrid vehicles and power supplies used in telecom sector. In order to utilize maximum energy from several available energy sources, such as fuel cell. battery, solar array and wind energy various multiple-input converter has been proposed in the recent year. Depending upon the applications one could select a feasible topology by considering many features like reliability, cost and flexibility. Multiple- input dc-dc converter has advantage of larger system efficiency, more power density, light weight and small size Some of the applications of multi-input converters have already been reported in $[1,2]$. Block diagram of two Input dc-dc converter is shown in Figure 1.

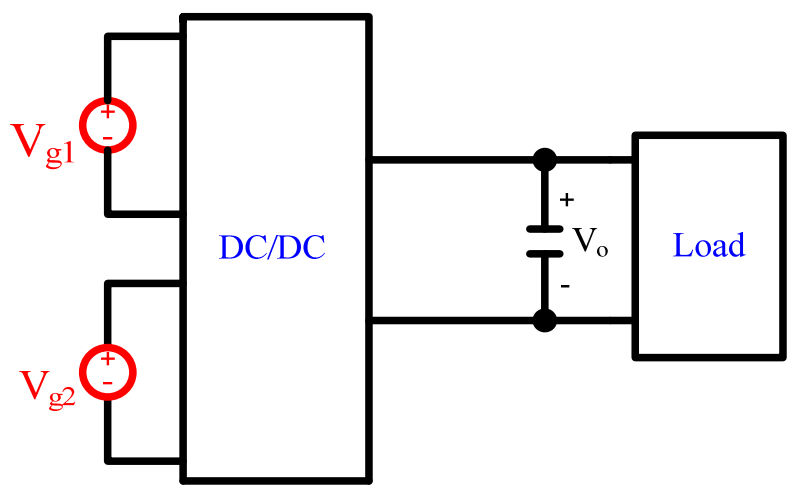

Fig. 1.. Block diagram of two-input integrated type DC-DC converter

Understanding of a dc-dc converter involves steady-state analysis and dynamic analysis of the converter [3]. The steady-state analysis is a useful tool in observing converter behavior under nominal conditions. It uses voltsec balance, charge-sec balance and principle of energy conservation. The dynamic analysis is carried out to know the system behavior for perturbation of any quantity. In this paper, the working of the proposed topology and the voltage- gain expressions for converter have been derived and elucidated. The state-space as well as discrete-time models of the converter are obtained and then small-signal transfer functions have been formulated $[4,5]$. With time-domain analysis and power invariance principle the converter components design expressions has been derived and the steady-state behavior of the system is simulated. Steady-state analysis is used to find the converter circuit parameters for the given specifications. For the proposed converter duty cycle $d_{2}$ is less than $d_{1}$ and the PWM gating signal is shown in Fig.2. 


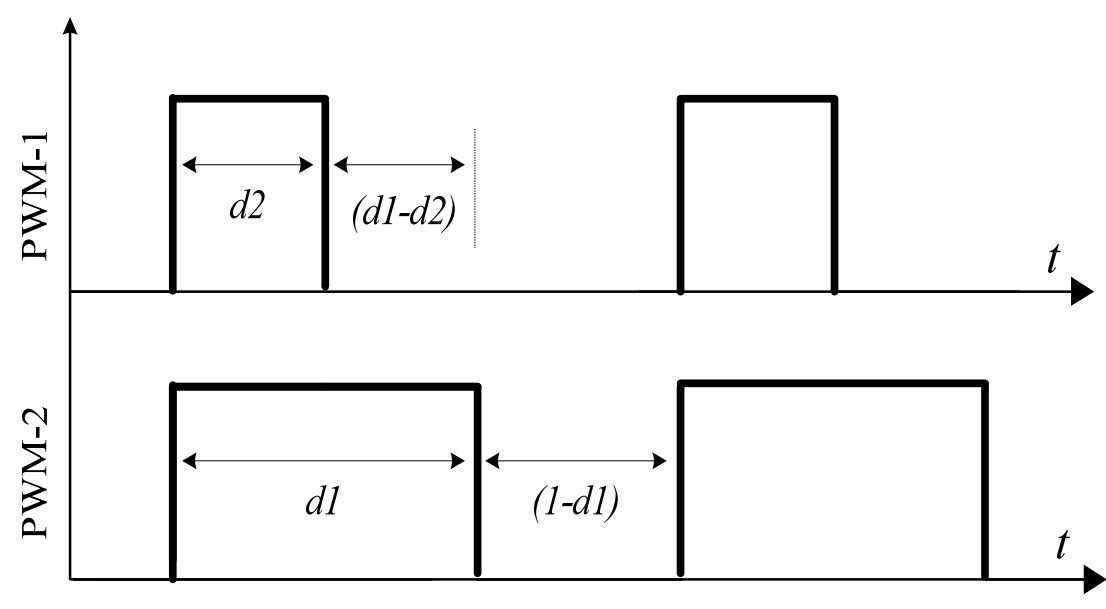

Fig.2 PWM gating signals $\left(d_{2}<d_{1}\right)$.

\section{PROPOSED CONVERTER}

The proposed converter is having two voltage sources and five energy storing elements making a fifth order system as shown in figure 3. The proposed converter is intended to be used in DC grid applications. Converter specifications may change depending upon the application requirement. In order to test the converter performance a prototype model is made in the laboratory. Converter can be redesigned for higher power requirements by following same approach. Converter specifications are given in Table.1.

Table. 1. Converter Specifications.

\begin{tabular}{|c|c|}
\hline Power rating & $\approx 200 \mathrm{~W}$ \\
\hline DC Load voltage & $48 \mathrm{~V}$ \\
\hline Source voltage & $24 \mathrm{~V}, 36 \mathrm{~V}$ \\
\hline Current ripple & $\leq 10 \%$ \\
\hline Voltage ripple & $\leq 5 \%$ \\
\hline Switching frequency & $50 \mathrm{kHz}$ \\
\hline
\end{tabular}

With these designed specifications tabulated using equations (1-2) parameters of the inductances and capacitances used in converter can be computed. The converter is designed for $176 \mathrm{~W}$ to meet the specifications given in Table 2.

Ripple current specification for the inductors are:

$$
\Delta i_{1}=10 \% \text { of } i_{L 1}, \Delta i_{2}=10 \% \text { of } i_{L 2}, \Delta i_{3}=10 \% \text { of } i_{L 3}
$$

Ripple voltage specification for the capacitors are:

$$
\Delta v_{c 1}=5 \% \text { of } V_{0}, \Delta v_{c 2}=5 \% \text { of } v_{0}
$$

With theses parameters and ripple specifications inductances and capacitances of the two-input boost-sepic converter has been computed, and the values are tabulated in Table. 2 .

Table. 2. Parameters of the converter.

\begin{tabular}{|c|c|}
\hline Parameter & Value \\
\hline$L_{1}$ & $300 \mu \mathrm{H}$ \\
\hline$L_{2}$ & $510 \mu \mathrm{H}$ \\
\hline$L_{3}$ & $700 \mu \mathrm{H}$ \\
\hline$C_{1}$ & $22 \mu \mathrm{F}$ \\
\hline$C_{2}$ & $47 \mu \mathrm{F}$ \\
\hline
\end{tabular}




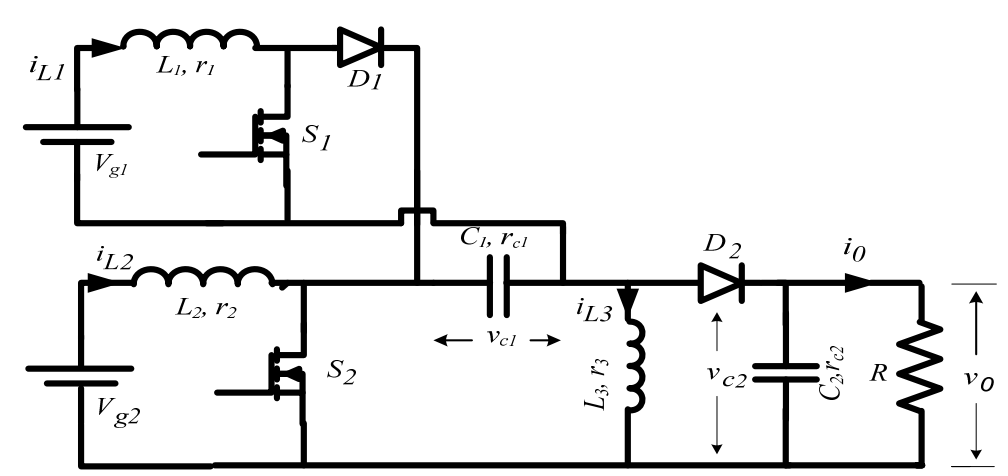

Fig. 3. DC-DC CONVERTER CIRCUIT DIAGRAM

The proposed two-input integrated converter is shown in figure 3. For this converter, three different cases may be possible: (1) source-1 delivers more power than source-2. (2) source-2 delivers more power than source-1 (3). Both the sources deliver same amount of power. The modeling of the converter has been carried out by taking the first case i.e. source-1 can deliver more power than source-2. So source-1 has to be operated for more time. Because of the limited power supply capacity of source 2, the duty cycle of the switch $\mathrm{S}_{2}\left(\mathrm{~d}_{2}\right)$ is assumed to be less than the duty cycle of the switch $\mathrm{S}_{1}\left(\mathrm{~d}_{1}\right)$. With this assumption, the PWM gating signals provided for the proposed converter is shown in Fig.4.

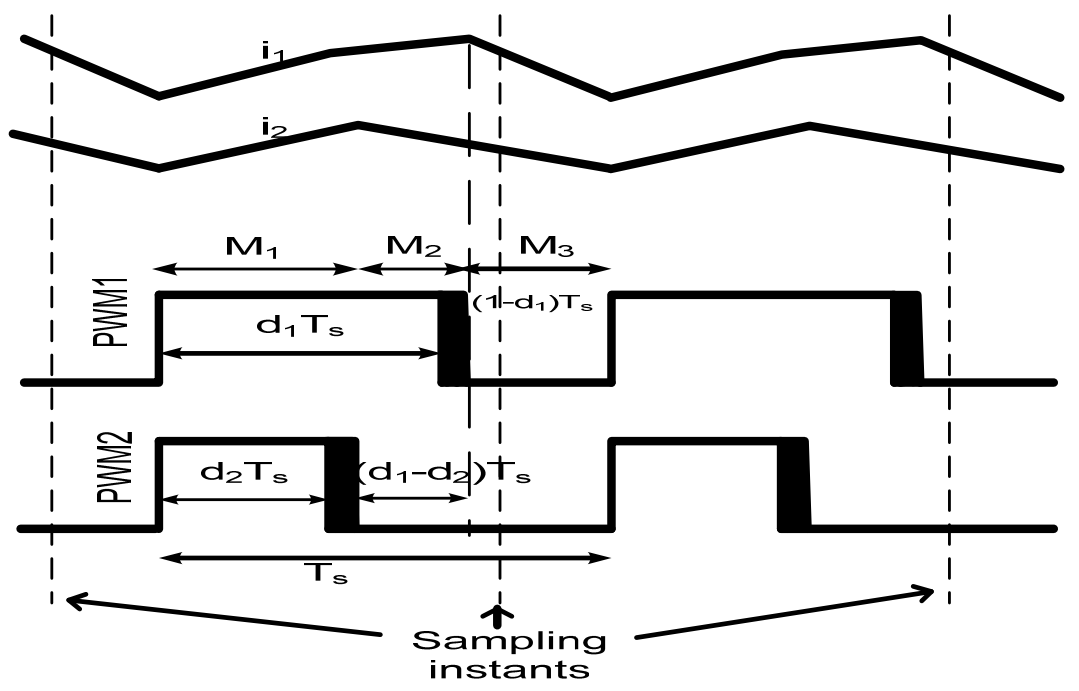

Fig.4 Sampling Process

\section{MODELING OF TWO-INPUT DC-DC CONVERTER}

In each mode of operation the power stage dynamics can easily be described by a set of state equations given by equation (3):

$$
\begin{aligned}
\dot{x} & =A_{K} x+B_{K} u \\
y & =C_{k} x+F_{k} u
\end{aligned}
$$

where $[x]=\left[\begin{array}{llll}i_{L 1} & i_{L 2} & v_{c 1} & v_{c 2}\end{array}\right]^{T},\left[\begin{array}{ll}u\end{array}\right]=\left[\begin{array}{ll}V_{g 1} & V_{g 2}\end{array}\right]^{T}$, and $\mathrm{k}=1,2,3$ for mode- 1 , mode- 2 and 3 , respectively.

\section{Digital Controller Design}

Several different types of control strategies are reported in literature Although the single-loop strategies are simple to implement, but their dynamic response times are slightly on higher side. Relative Gain Array (RGA) is an analytical tool used to determine the optimal input-output variable pairings for a multi-input-multi-output (MIMO) system. In other words, the RGA is a normalized form of the gain matrix that describes the impact of each control variable on the output relative to each control variable's impact on other variables. The process interactions of open-loop and closed-loop control systems are measured for all possible input-output variable pairings. In any case the digital compensator is designed using sisotool of the MATLAB in the frequency domain. Pole-zero placement technique is used and then final design is arrived. Fine tuning of the compensator is performed to ensure relative stability margins, i.e. gain margin $>6 \mathrm{~dB}, 35^{\circ}<$ phase margin $<75^{\circ}$ and reasonable crossover frequency, which normally depends on the order of the converter under consideration. A decentralized controller as shown in figure 5 has been designed for proposed converter. 


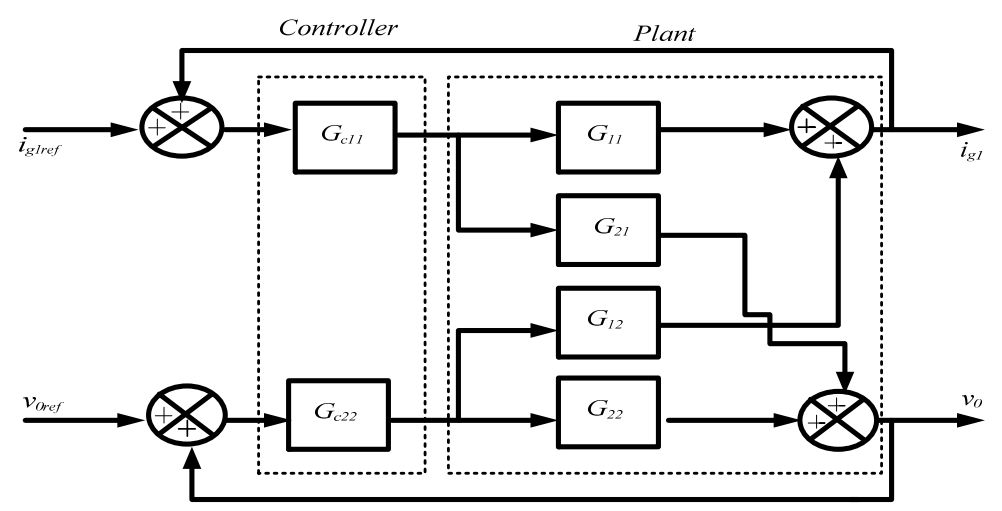

Fig. 5. De-centralized digital controller.

\section{RESUlts}

A $176 \mathrm{~W}$ two-input integrated converter with specifications mentioned in Table.1 is formulated and simulated in PSIM [12]. Initially the two voltage sources are set to $V_{g l}=24 \mathrm{~V}, V_{g 2}=36 \mathrm{~V}$ and duty ratio of switch $S_{1}$ and $S_{2}$ are adjusted to 0.4 and 0.6 respectively. Figure 6 shows the load voltage variation with source voltage variation.

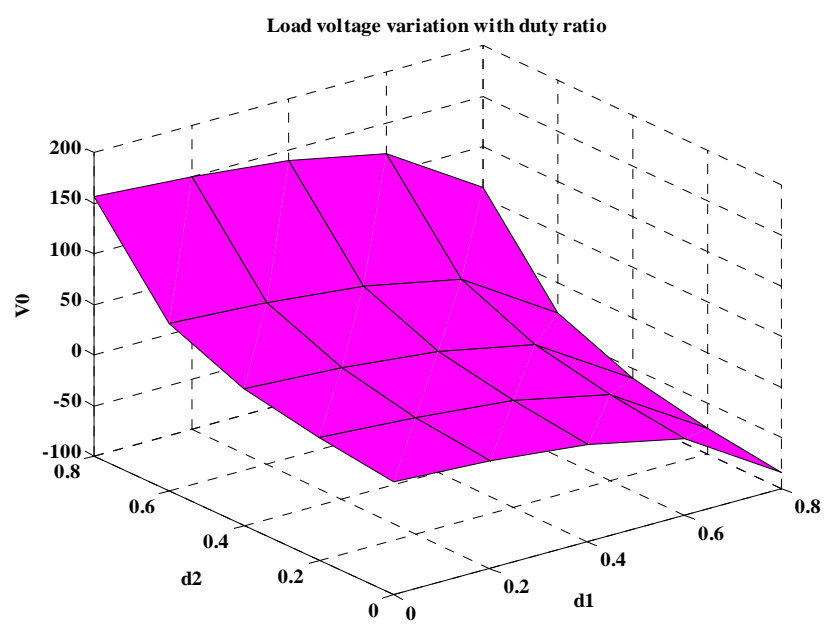

Fig. 6. Load voltage variation against duty ratio $\left(d_{1}, d_{2}\right)$.

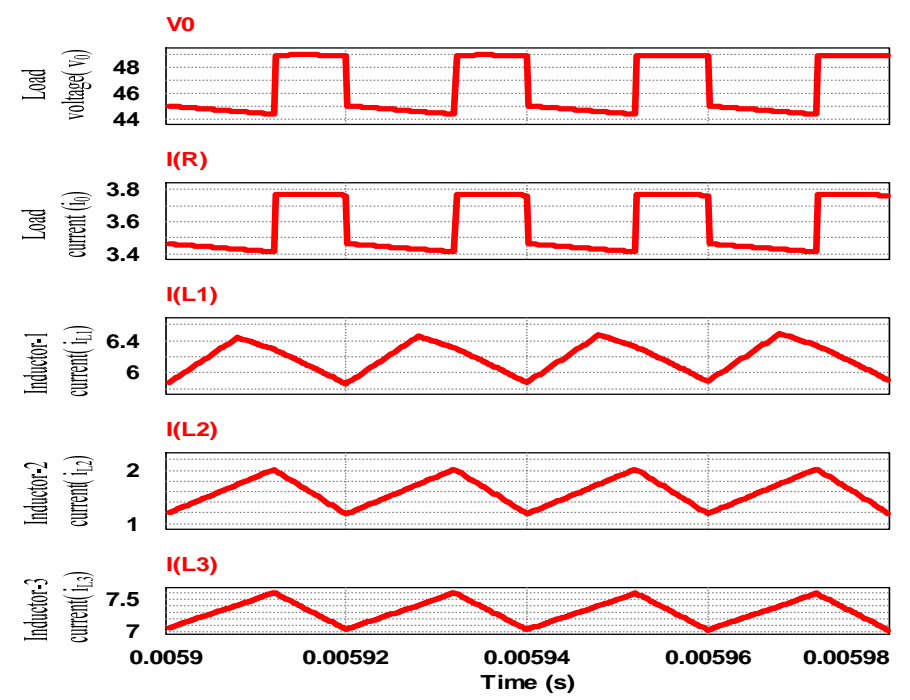

Fig.7(a) Converter Performance (open loop) 
Figures.7a) and 7b) show the converter performance during open loop and close loop respectively when both sources $\left(V_{g l}, V_{g 2}\right)$ are supplying power to the load. After addition of source-1, current drawn by source-2 is going to reduce and load demand is handled by both the sources.
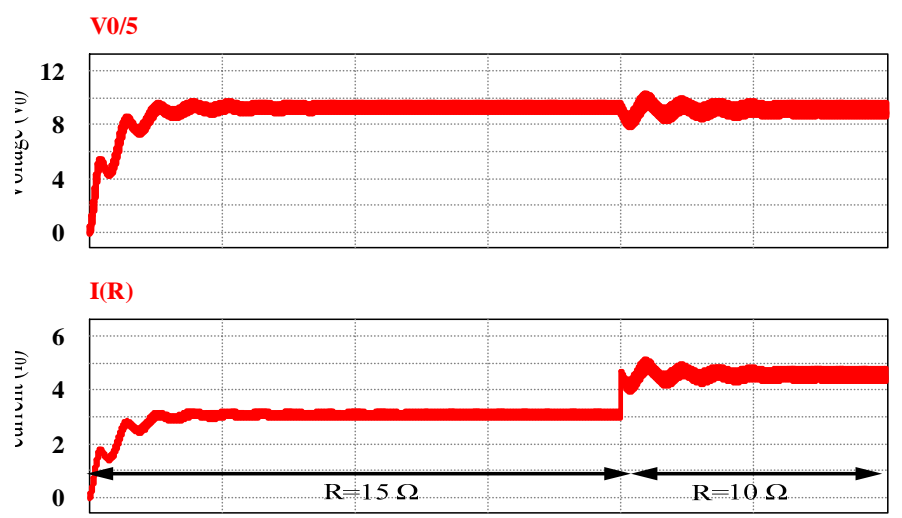

I(L2)

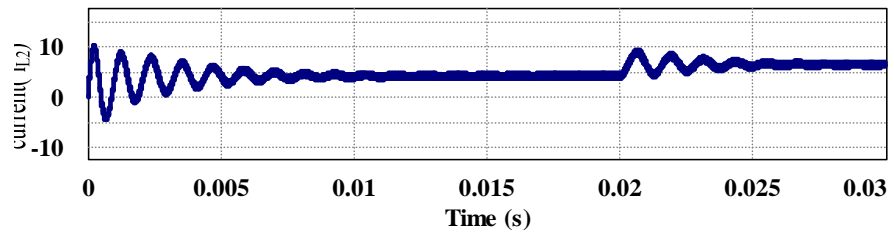

Fig.7(b) Converter performance ( Closed loop)

From the results shown in figures 7a) and 7b), sudden load variation from 15 to $10 \Omega$ (when only source-2 is present) at $t=20 \mathrm{msec}$, load voltage transients are settling down in $3.5 \mathrm{msec}$, whereas in order to fulfill the increased load demand source-2 current increases and getting settled in $5 \mathrm{msec}$. This concludes that designed converter regulates load voltage and source current.

\section{ConClusion}

A Multiple input DC-DC converter suitable for drawing power from two different dc sources and feeding to common dc load was proposed in this paper. The controller robustness has been verified for the source and load disturbances as the controller is producing output load voltage and source-1 current constant. Steady-state and dynamic response of the converter have been analyzed. Converter performance has been verified by sudden addition and removal of source-1. From the simulation and experimental comparisons it can be concluded that Theoretical results are in close agreement with PSIM simulation results.

\section{REFERENCES}

[1] Hirofumi Matsuo, Wenzhong Lin, Fujio Kurokawa, Tetsuro Shigemizu, Nobuya Watanabe, "Characteristics of the Multiple-Input DC-DC Converter," IEEE Trans. on Ind. Electron, vol. 51, no. 3, Jun. 2004pp.625-631.

[2] Jian Liu, Zhiming Chen, Zhong Du, "A new design of power supplies for pocket computer system”, IEEE Trans. on Ind. Electronics, Vol. 45(2), 1998, pp. 228-234.

[3] Anmol Ratna Saxena; M. Veerachary "converter"2016 IEEE 1st International Conference on Power Electronics, Intelligent Control and Energy Systems (ICPEICES)Year: 2016 Pages: $1-6$

[4] R. D. Middlebrook, Cuk. S, "A general unified approach to modelling switching converter power stage", Proceedings of IEEE Power Electronics Specialists Conference, 1976, pp. 13-34.

[5] D. Maksimovic and R. Zane, "Small-Signal Discrete Time Modeling of Digitally Controlled PWM Converters", IEEE Trans. on Power Electronics, vol. 22, no. 6, Jun. 2007, pp. 2552-2556.

[6] Krishna Mohan. B, "Robust Digital Voltage Mode Controller for Fifth-Order Boost Converter," IEEE Trans. Industrial Electron., vol. 58, no. 1, Jan.2010, pp. 263-277.

[7] M. Veerachary, "Two-loop controlled buck-SEPIC converter for input source power management," IEEE Trans. On Industrial Electronics, Vol. 59(11), 2012, pp. 4075-4087.

[8] Veerachary. Mummadi, Ramakanth Naidu Gowra, and Dileep Ganta. "Discrete-time modeling of multi-state DC-DC converters." Proc. of IEEE conference on Power Electronics, Drives and Energy Systems (PEDES) \& Power India, 2010, pp. 1-6.

[9] Maksimovic Dragan, and Regan Zane. "Small-signal discrete-time modeling of digitally controlled PWM converters.", IEEE Trans. on Power Electronics., vol.22(6), 2007, pp. 2552-2556.

[10] B. Amarendra Reddy; Mummadi Veerachary "Robust multivariable controller design using H-infinity Loop shaping for TIFOI DC-DC converter" IEEE Uttar Pradesh Section International Conference on Electrical, Computer and Electronics Engineering (UPCON) Year 2016 pp: $372-377$

[11] Mummadi Veerachary "Two-Switch Semiquadratic Buck Converter" IEEE Transactions on Industrial Electronics Year: 2017, Volume: 64, Issue: 2 Pages: 1185 - 1194,

[12] MATLAB user manual, 2000.

[13] PSIM, user manual, 2004. 